ORIGINAL ARTICLE

\title{
Twenty five year mortality and air pollution: results from the French PAARC survey
}

\author{
L Filleul, V Rondeau, S Vandentorren, N Le Moual, A Cantagrel, I Annesi-Maesano, D Charpin, \\ C Declercq, F Neukirch, C Paris, D Vervloet, P Brochard, J-F Tessier, F Kauffmann, I Baldi
}

Occup Environ Med 2005;62:453-460. doi: 10.1136/oem.2004.014746

See end of article for authors' affiliations

.....................

Correspondence to: Dr L Filleul, Laboratoire Santé Travail

Environnement, Université Victor Ségalen Bordeaux 2,146 rue Léo Saignat, 33076 Bordeaux cedex, France; laurent.filleul@ sante.gouv.fr

Accepted 1 December 2004
Aims and Methods: Long term effects of air pollution on mortality were studied in 14284 adults who resided in 24 areas from seven French cities when enrolled in the PAARC survey (air pollution and chronic respiratory diseases) in 1974. Daily measurements of sulphur dioxide, total suspended particles, black smoke, nitrogen dioxide, and nitric oxide were made in 24 areas for three years (1974-76). Cox proportional hazards models controlling for individual confounders (smoking, educational level, body mass index, occupational exposure) were applied, and frailty models used to take into account spatial correlation. Indicators of air pollution were the mean concentration.

Results: Models were run before and after exclusion of six area monitors influenced by local traffic (NO/ $\mathrm{NO}_{2}>3$ in ppb). After exclusion of these areas, analyses showed that adjusted risk ratios $(95 \% \mathrm{Cl})$ for TSP, $\mathrm{BS}, \mathrm{NO}_{2}$, and $\mathrm{NO}$ for non-accidental mortality were 1.05 (1.02 to 1.08), 1.07 (1.03 to 1.10), 1.14 (1.03 to 1.25 ), and 1.11 (1.05 to 1.17$)$ for $10 \mu \mathrm{g} / \mathrm{m}^{3}$ respectively. Consistent patterns for lung cancer and cardiopulmonary causes were observed.

Conclusions: Urban air pollution assessed in the 1970s was associated with increased mortality over 25 years in France.
$\mathrm{S}$ hort term associations between temporal day-to-day variations in outdoor air pollutants concentrations and day-to-day variations in total and cause specific mortality have been evidenced by many time series in the last decade. ${ }^{1-3}$ Long term effects of air pollution on mortality have been evaluated in three American prospective cohort studies. The Harvard Six Cities study followed over 15 years a cohort of 8111 adults. ${ }^{4}$ The American Cancer Society (ACS) study followed prospectively from 1982 to 1989 a cohort of 552138 adults. ${ }^{5}$ The Adventist Health Study of Smog (ASHMOG study) followed a cohort of 6338 non-smoking California Seventh-day Adventists (SDAs) since 1997. ${ }^{6}$ After controlling for age, sex, cigarette smoking, educational level, body mass index, and other risk factors, results showed that relatively low concentrations of fine particles could be associated with reduced survival. Cardiopulmonary mortality was significantly associated with concentrations of particulate air pollution in the Six Cities study ${ }^{4}$ and in the ACS, ${ }^{5}$ but not in the ASHMOG study. ${ }^{6}$

A recent paper doubled the follow up time to more than 16 years for the ACS study and concluded that long term exposure to combustion related fine particulate air pollution is an important environmental factor for cardiopulmonary and lung cancer mortality. ${ }^{7}$ However, these studies have been conducted in North America, and only one study has been published on long term effects from the Netherlands Cohort study on Diet and Cancer (NLCS) in Europe. ${ }^{8}$ The authors followed up 5000 adults aged 55-69 years over eight years; results showed that cardiopulmonary mortality was associated with living near a major road, with a relative risk of 1.95 (95\% CI 1.09 to 3.52 ).

Based on the $\mathrm{PM}_{10}$ (particles with an aerodynamic diameter $<10 \mu \mathrm{m}$ ) data from these American studies, a recent report estimated the health impact of outdoor air pollution, including pollution specifically from road traffic in France, ${ }^{9}$ and the authors noted the limitation of using data from the USA where air pollution is different from that in Europe.
The initial aim of the PAARC survey (Pollution Atmosphérique et Affections Respiratoires Chroniques/Air pollution and chronic respiratory diseases) conducted in 24 areas of seven French towns in 1975-76 was to investigate the effect of air pollution on chronic respiratory diseases. ${ }^{10-12}$ The aim of the present analysis was to estimate long term effects of air pollution on mortality in a large sample of the French population with a specific interest in aspects modifying the effect estimates. Analyses have been performed taking into account individual risk factors, various indicators or air pollution (and in particular an indicator of traffic pollution), and potential spatial clustering.

\section{METHODS}

\section{Study population}

The detailed protocol of the PAARC study was published elsewhere. ${ }^{10}$ Briefly, 24 areas in seven French towns (Bordeaux, Lille, Lyon, Mantes la Jolie, Marseille, Rouen, Toulouse) were selected.

The choice of the areas was based on a three step procedure. First, based on 1961-71 available air pollution data in the seven cities (availability of such data in 1971 was a preliminary condition for the various cities to participate), a first choice of contrasted measurement points was made in order to have quantitative (low, intermediate, high) and qualitative (acidimetric method and black smoke) contrasted pollution between the various points of measurement, and when possible between points of each city. In a second step, areas were chosen around potential measurement points, taking into account all available information on pollution and feasibility regarding population density in the areas, using 1968 census data. In a third step, air pollution measures were set up in these areas with standard methods, and a quality control programme was set up in parallel with a pilot survey conducted on a $10 \%$ sample of the planned survey.

Inclusion criteria for enrolment between 1974 and 1976 were: being a member of a French family household in the 
Main messages

- The PAARC survey shows that urban air pollution assessed in the 1970s is associated with increased mortality over 25 years.

- Inclusion of air monitoring data from stations directly influenced by local traffic can overestimate the mean population exposure and bias the results.

area for three years or more, and aged 25-59 years. The head of the family that was a manual worker was excluded to avoid masking the effect of air pollution because of another heavy exposure. In a face to face interview, a questionnaire was completed which included questions about age, sex, weight, height, smoking history, occupational exposures, and other characteristics. The mobility of the population during the follow up period (1974-2000) was assessed for a 10\% randomised sample of the population ${ }^{13}$ by searching the subjects on national phone files in 2000, using name, first name, and address in 1974.

\section{Air pollution exposure assessment}

Specific standardised measurements sites were set up for each chosen area $^{10}$ in 1974; each area varied in diameter from 0.5 to $2.3 \mathrm{~km}$. Pollutants were selected and measured according to the epidemiological knowledge and methods available in the 1970s; they essentially reflected pollution due to combustion of fossil fuels in industrial and domestic use. Sulphur dioxide (specific $\left(\mathrm{SO}_{2}\right)$ and acidimetric method $(\mathrm{AM})$ ), total suspended particles (TSP, gravimetric method), black smoke (BS, reflectometry), nitrogen dioxide $\left(\mathrm{NO}_{2}\right.$, colorimetric analyser), and nitric oxide (NO, colorimetric analyser) were measured in each area at a centrally located pollution monitoring station. All analyses were made in local laboratories according to validated methods with a control programme implemented to compare labs: differences between labs were reported to be small. Measurements were performed every day except in August during three years (1974-76) for all pollutants except sulphates which were measured in smaller periods (12-36 months). Means over this period were used in statistical analysis.

A study based on an overlapping period (3-4 years) of measurements by two air pollution networks in Bordeaux showed a marked decrease in the heterogeneity of air pollutants over the 25 year period for each area, but keeping the initial ranking of the areas. Results also showed that differences between areas occurred mostly before the initial survey and in the following five years. ${ }^{14}$

\section{Vital status}

Vital status was first searched for all subjects born in France (17 805 subjects) over three years (1995-98) in each place of birth, in some cases by a specific investigator. Data were completed using a new facility allowing a computerised search through a national register (RNIPP). Two computerised searches were performed (August 2000 and June 2001 after extensive data checking). Unknown vital status primarily related to sex, with significantly more unknown status for women due to changes in surname, but was unrelated to air pollution. From the original data, all persons included by one investigator in Lille were excluded, as too many data appeared invalid (900 subjects, 5\%). Vital status was available until June 2001 (2533 deaths, 11753 alive, and 2619 unknown), and cause of death until December 1998. Causes of death were obtained through the specialised department (SC8) of the National Institute of Health and Medical

\section{Policy implications}

- The PAARC study confirms previous results on long term effect of air pollution on mortality.

- Additional long term studies with a fine exposure assessment are needed for the development of effective policies.

Research (INSERM) and for 96\% of subjects. They were coded according to the International Classification of Disease, eight and ninth Revision codes (ICD-8 and -9).

\section{Confounders}

Confounders taken into account were sex, smoking habits, educational level, body mass index (weight/height ${ }^{2}$ ), and occupational exposure to dust, gases, and fumes estimated by a population based job exposure matrix (JEM). ${ }^{15}$ For each job present in the population, the proportion of subjects exposed to dusts, gases, and fumes using the self-reported dichotomous variable was calculated by sex. A two class JEM was then built by considering as exposed any job for which more than " $\mathrm{x}$ " per cent of the subjects with this job reported themselves exposed, choosing " $\mathrm{x}$ " in such a way that the prevalence of exposure was the same using the JEM and the self-reported data. ${ }^{15}$ Smoking habits considered were non-smokers, passive smokers (exposure by the spouse), former smokers, and current smokers with $\leqslant 9 \mathrm{~g} /$ day, 10 to $\leqslant 19 \mathrm{~g} /$ day, and $\geqslant 20 \mathrm{~g} /$ day as cigarettes, cigars, or pipe. ${ }^{16}$ Educational level was classified as primary, secondary, and university level.

\section{Statistical analysis}

Adjusted mortality relative risks (RRa) were estimated using Cox proportional hazards regression models, ${ }^{17}$ using Proc Phreg from SAS 6.8 (SAS Institute, Inc., Cary, North Carolina) using models with delayed entry to take into account left truncation. ${ }^{18}$ Age was chosen as the basic time scale in order to adjust the mortality risk non-parametrically for age. ${ }^{19}$ For subjects who died, survival times were age at date of death. For surviving participants who were not lost to follow up, censored survival times were age at the date of the collection of vital status. Subjects without vital status were considered lost to follow up and excluded. Models were run for each pollutant separately. Air pollutant level (continuous variable) and three categorical indicators (below or above the median, quartiles, or area (24 class variable) were used in all analyses. Analyses were conducted to evaluate the robustness of the models. Models were performed according to age, sex, smoking habits, body mass index, educational level, occupational exposure, and stratified by. Cox proportional hazard models were estimated for all non-accidental causes of deaths (ICD-9 codes <800) and separately for the cause-ofdeath categories: cardiopulmonary disease (ICD-9: 401-440 and 460-519) and lung cancer (ICD-9: 162). For each causeof-death, deaths not in that specific category were censored at time of death. Analyses were also run for the first 10 years to decrease the influence of the mobility of the subjects and because air pollution levels in the different areas tend to become homogeneous in the recent period.

The PAARC survey design incorporates a grouping of the participants into 24 areas from seven cities, and this may induce a correlation of the observations. It is therefore possible that some unmeasured environmental or socioeconomic factors shared by the members of the same areas could play a confounding role. Analysis of dependent survival data by the classical Cox proportional hazard model using 
Table 1 Air pollution levels in the PAARC cities in 1974-76 and 1990-97

\begin{tabular}{|c|c|c|c|c|c|c|c|c|c|c|c|c|}
\hline \multirow[b]{2}{*}{ Cities } & \multirow[b]{2}{*}{ Areas } & \multicolumn{2}{|c|}{$\begin{array}{l}\text { Evaluation of the } \\
\text { representativeness } \\
(1974-76)\end{array}$} & \multicolumn{5}{|c|}{$1974-76$ (means levels in $\mu \mathrm{g} / \mathrm{m}^{3}$ ) } & \multirow{2}{*}{$\begin{array}{l}1978- \\
81 \\
\text { BS }\end{array}$} & \multicolumn{3}{|c|}{$\begin{array}{l}1990-97 \text { (median levels in } \\
\mu \mathrm{g} / \mathrm{m}^{3} \text { ) for all the city }\end{array}$} \\
\hline & & Good & $\begin{array}{l}\text { Heavy } \\
\text { traffic }\end{array}$ & BS & $\mathrm{SO}_{2}$ & $\mathrm{SO}_{2}-\mathrm{AM}$ & $\mathrm{NO}_{2}$ & $\begin{array}{l}\mathrm{NO} / \mathrm{NO}_{2} \\
>3\end{array}$ & & BS & $\mathrm{SO}_{2}{ }^{*}$ & $\mathrm{NO}_{2}$ \\
\hline \multirow[t]{4}{*}{ Bordeaux } & Area 1 & Yes & No & 31 & 33 & 42 & 21 & No & 20.0 & & & \\
\hline & Area 2 & Yes & No & 31 & 27 & 37 & 17 & No & 19.9 & & & \\
\hline & Area 3 & No & Yes & 105 & 52 & 69 & 42 & Yes & 72.7 & 13.0 & 8.5 & NA \\
\hline & Area 4 & Yes & No & 67 & 47 & 47 & 32 & No & 43.2 & & & \\
\hline \multirow[t]{4}{*}{ Lille } & Area 1 & Yes & No & 52 & 58 & 71 & 27 & No & & & & \\
\hline & Area 2 & Yes & No & 61 & 46 & 66 & 22 & No & & & & \\
\hline & Area 3 & NA & No & 50 & 17 & 85 & 19 & No & NA & 14.4 & 19.3 & 33.8 \\
\hline & Area 4 & NA & No & 28 & 21 & 36 & 19 & No & & & & \\
\hline \multirow[t]{4}{*}{ Lyon } & Area 1 & Yes & No & 77 & 63 & 88 & 24 & No & & & & \\
\hline & Area 2 & Yes & No & 57 & 72 & 100 & 14 & No & & & & \\
\hline & Area 3 & Yes & No & 39 & 45 & 56 & 12 & No & NA & NA & 14.7 & 47.1 \\
\hline & Area 4 & Yes & No & 60 & 80 & 94 & 23 & No & & & & \\
\hline \multirow[t]{2}{*}{ Mantes } & Area 1 & Yes & No & 40 & 37 & 55 & 26 & No & & & & \\
\hline & Area 2 & Yes & No & 35 & 40 & 49 & 22 & No & NA & NA & NA & NA \\
\hline \multirow[t]{4}{*}{ Marseille } & Area 1 & No & Yes & 46 & 35 & 60 & 13 & No & & & & \\
\hline & Area 2 & No & Yes & 141 & 55 & 105 & 34 & Yes & & & & \\
\hline & Area 3 & Yes & No & 152 & 85 & 120 & 35 & Yes & NA & 14.0 & 14.0 & 32.0 \\
\hline & Area 4 & Yes & No & 44 & 36 & 48 & 13 & No & & & & \\
\hline \multirow[t]{3}{*}{ Rouen } & Area 1 & Yes & No & 21 & 34 & 64 & 18 & No & & & & \\
\hline & Area 2 & NA & No & 36 & 32 & 127 & 23 & No & NA & 9.8 & 23.4 & 30.7 \\
\hline & Area 3 & Yes & No & 18 & 73 & 109 & 19 & No & & & & \\
\hline \multirow{3}{*}{ Toulouse } & Area 1 & No & Yes & 111 & 25 & 32 & 61 & Yes & & & & \\
\hline & Area 2 & Yes & No & 85 & 23 & 34 & 42 & Yes & NA & NA & 10.0 & 28.3 \\
\hline & Area 3 & No & Yes & 91 & 22 & 13 & 40 & Yes & & & & \\
\hline
\end{tabular}

conventional partial likelihood methods may give a biased estimate of the regression coefficient and underestimate their variance, leading to incorrect inferences. We thus considered a "frailty model" to take into account the grouping of the subjects in the different geographical areas. In this random effects model, the hazard function depends partly on an unobservable random variable thought to act multiplicatively on the hazard. The survival package developed for $\mathrm{R}^{20}$ (http:// www.cran.r-project.org/) has been used to implement the frailty models. This approach, first developed by Therneau for
S, used a penalised likelihood to estimate the parameters. ${ }^{21}$ We have tested heterogeneity of the survival times between the areas and also between the cities.

The analyses have been performed systematically for all 24 areas and in the subgroup of 18 areas defined by a ratio of $\mathrm{NO} / \mathrm{NO}_{2}<3$ (in ppb), corresponding to monitoring stations not traffic dependent according to ADEME criteria. ${ }^{22}$ The six areas excluded were Bordeaux3, Marseille2, Marseille3, Toulousel, Toulouse2, and Toulouse3, for which $\mathrm{NO} / \mathrm{NO}_{2}$ varied between 2.25 (Toulouse 3) and 4.26 (Marseille 2).

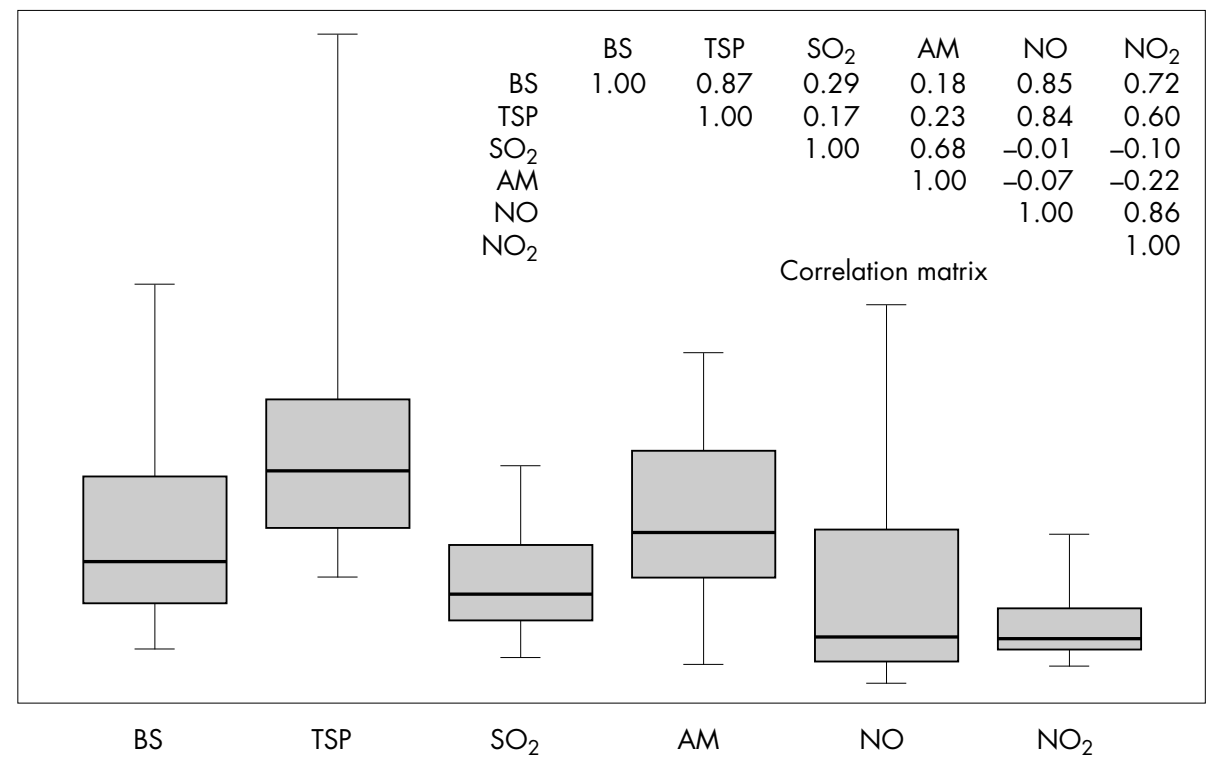

Figure 1 Air pollution levels (in $\mu \mathrm{g} / \mathrm{m}^{3}$ ) based on three year average of daily measurements (1974-76) in 24 areas, France. Box plots (first quartile, median, third quartile). BS, black smoke; TSP, total suspended particles; $\mathrm{SO}_{2}$, sulphur dioxide; $\mathrm{AM}$, acidimetric method; $\mathrm{NO}_{2}$, nitrogen dioxide; $\mathrm{NO}$, nitric dioxide. 


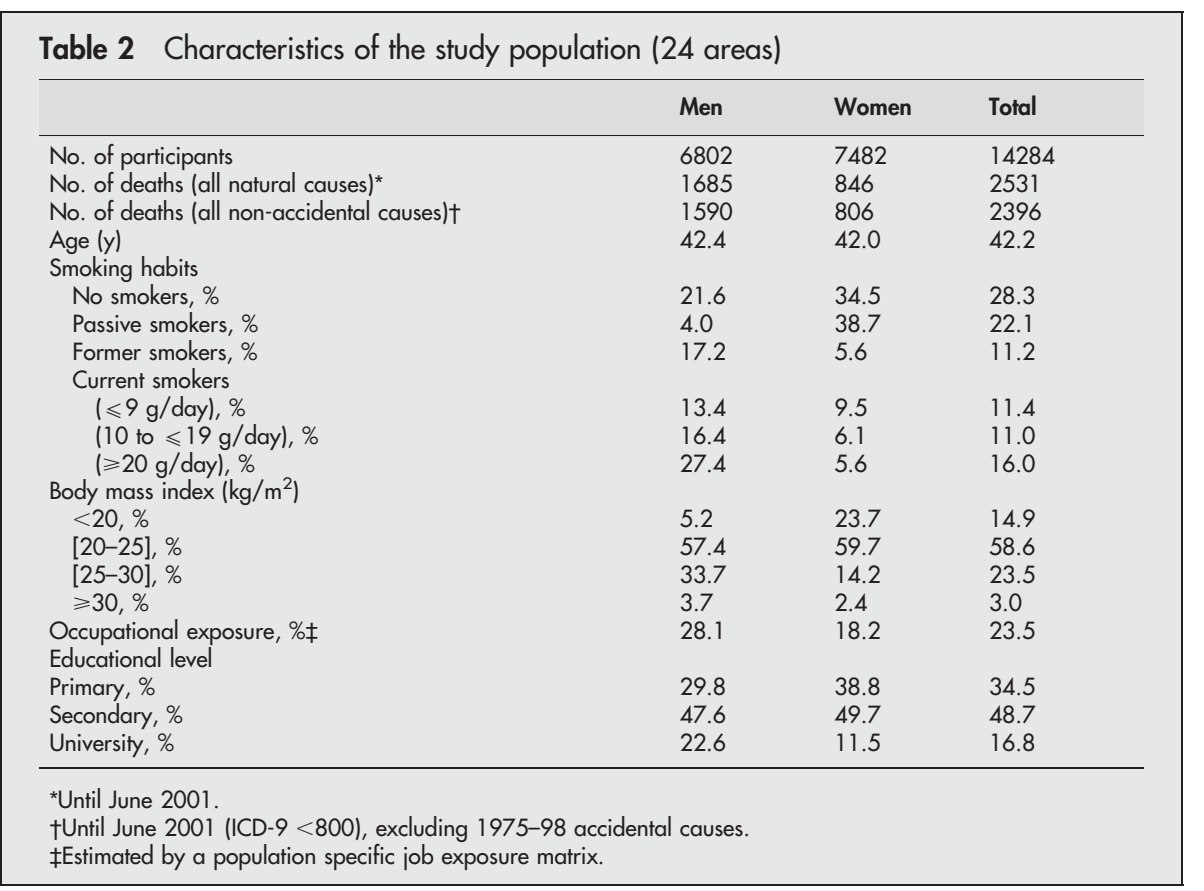

\section{RESULTS}

\section{Characteristics of air pollution and population data}

Air pollution levels for all areas are presented in table 1. Available information regarding representativeness is mentioned as well as the evolution of pollution with available data. Data for the various areas has not been available until now; background levels for the period 1990-97 in six of the seven cities from the Programme de surveillance Air et santé $(\text { PSAS-9 })^{23}$ study shows a general decrease in black smoke and sulphur dioxide levels for all cities. For $\mathrm{NO}_{2}$, there is a decrease for Toulouse and an increase for Lyon, Rouen, and Marseille (table 1).

Area variations were the largest for TSP, ranging from 45 to $243 \mu \mathrm{g} / \mathrm{m}^{3}$, and the lowest for $\mathrm{NO}_{2}$, ranging from 12.0 to $61.0 \mu \mathrm{g} / \mathrm{m}^{3}$ (fig 1). Correlation between BS and TSP concentrations was 0.87 , and between $\mathrm{AM}$ and $\mathrm{SO}_{2}$ was 0.68 (24 areas, see fig 1). Vital status was available for 14284 adults (table 2). Until June 2001, 2531 subjects died; excluding 1975-98 accidental causes, 2396 (1590 males, 806 females) deaths for all non-accidental causes occurred. Until December 1998, 546 cardiopulmonary (140 in women and 406 in men) and 178 lung cancer deaths (25 in women and 153 in men) were recorded. Results of the mobility study showed that after 25 years, $60 \%$ still lived in the same region (French "département"), $41 \%$ in the same town, with $23.4 \%$ in the same area and $17.1 \%$ in another area.

\section{Factors associated with mortality}

Mortality risk was higher for men than for women: $\mathrm{RR}=2.33$ (95\% CI 2.14 to 2.53 ) and strongly associated with smoking habits. Risk of all-cause mortality was significantly higher in the smokers groups, particularly in the heavy smokers, than in no smokers, and very high for specific causes, particularly lung cancer (able 3). Mortality was also significantly related to occupational exposure: $\mathrm{RR}=1.27$ (95\% CI 1.16 to 1.40 ).

Table 4 shows the difference between results based on 24 areas and 18 areas respectively. No association was observed for the 24 areas. By contrast, after excluding the six areas with high $\mathrm{NO} / \mathrm{NO}_{2}$ ratios $(>3)$, associations between air pollutants and mortality were evidenced. Subjects from the 18 areas compared to the other six areas had similar smoking habits and body mass index, were significantly younger $(42.0$ $v 42.6$ years), more often occupationally exposed (24.2 v
22.0), and had lower educational level (15.6 $v 19.5$ with a university degree). All these variables were included in multivariate analyses. Before adjusting for confounders, exposure to TSP, BS, and $\mathrm{NO}_{2}$ was significantly associated with all-cause mortality, exposure to $\mathrm{NO}_{2}$ with lung cancer mortality, and exposure to TSP with cardiopulmonary mortality.

Multivariate analysis was conducted for each pollutant using the mean concentrations for the period 1974-76. After adjusting for age, sex, body mass index, educational level, smoking habits, and occupational exposure, TSP, $\mathrm{BS}, \mathrm{NO}_{2}$, and NO were significantly associated with all non-accidental mortality: RRa associated with $10 \mu \mathrm{g} / \mathrm{m}^{3}$ changes in pollutant were 1.05 (1.02 to 1.08 ), 1.07 (1.03 to 1.10$), 1.14$ (1.03 to $1.25)$, and 1.11 (1.05 to 1.17 ), respectively (table 4 ).

We observed a significant positive association between $\mathrm{NO}_{2}$ and lung cancer: RRa associated with a $10 \mu \mathrm{g} / \mathrm{m}^{3}$ changes in pollutant was 1.48 ( 1.05 to 2.06 ). Cardiopulmonary mortality was associated with $\mathrm{NO}_{2}$ : RRa associated with a $10 \mu \mathrm{g} / \mathrm{m}^{3}$ changes in pollutant was 1.27 (1.04 to 1.56) (table 4).

Figure 2 presents air pollution related mortality RR ratios after stratifying by sex, smoking habits, occupational exposure, educational level, and adjusting for all other risk factors. The differences across sex strata were not consistent according to air pollutants and causes of death.

A pattern emerged from this analysis: the association with air pollution and all-cause mortality was stronger for subjects with occupational exposure. Also, for all-cause, cardiopulmonary, and lung cancer mortality, the RR estimates were higher for current or former smokers. We observed a significant positive association with TSP air pollution for both allcause and cardiopulmonary mortality for participants with less education.

\section{Spatial clustering}

When studying the non-accidental mortality, the variance of the frailty parameters, for cities as areas were significantly different from zero after adjustment. This means that it remains a geographical correlation of the survival data even after adjustment. However we did not observe major changes in the estimates; the standard errors of the air pollution effects were not modified except for $\mathrm{NO}_{2}$ and NO. No heterogeneity between areas was observed on the lung cancer 
Table 3 Mortality relative risks (and 95\% confidence intervals) according to smoking habits (24 areas)

\begin{tabular}{|c|c|c|c|}
\hline Smoking habits & All subjects* & Ment & Woment \\
\hline \multicolumn{4}{|l|}{ All non-accidental causes } \\
\hline No smokers & 1.00 & 1.00 & 1.00 \\
\hline Passive smokers & 0.92 (0.79 to 1.06$)$ & $0.77(0.52$ to 1.16$)$ & $0.88(0.75$ to 1.04$)$ \\
\hline Former smokers & $1.13(0.97$ to 1.31$)$ & 1.28 (1.07 to 1.54$)$ & 0.86 (0.60 to 1.22$)$ \\
\hline Current smokers ( $\leqslant 9 \mathrm{~g} /$ day) & $1.08(0.92$ to 1.26$)$ & $1.19(0.97$ to 1.45$)$ & $1.02(0.78$ to 1.32$)$ \\
\hline Current smokers ( 10 to $\leqslant 19 \mathrm{~g} /$ day $)$ & 1.55 (1.34 to 1.79 ) & 1.79 (1.50 to 2.14$)$ & $1.16(0.85$ to 1.58$)$ \\
\hline Current smokers $(\geqslant 20 \mathrm{~g} /$ day) & 2.65 (2.34 to 2.99 ) & $2.99(2.56$ to 3.50$)$ & 2.02 (1.55 to 2.65 ) \\
\hline \multicolumn{4}{|l|}{ Lung cancer } \\
\hline No smokers & 1.00 & 1.00 & 1.00 \\
\hline Passive smokers & $1.06(0.31$ to 3.68$)$ & $1.53(0.17$ to 13.69$)$ & $1.10(0.22$ to 5.48$)$ \\
\hline Former smokers & $2.57(0.97$ to 6.86$)$ & 2.44 (0.75 to 7.93$)$ & $2.65(0.28$ to 25.56$)$ \\
\hline Current smokers ( $\leqslant 9 \mathrm{~g} /$ day) & 2.88 (1.07 to 7.78$)$ & $2.32(0.66$ to 8.23$)$ & $5.04(1.01$ to 25.14$)$ \\
\hline Current smokers ( 10 to $\leqslant 19 \mathrm{~g} /$ day) & $11.71(5.14$ to 26.70$)$ & 10.58 (3.73 to 30.03 ) & 16.59 (4.12 to 66.84$)$ \\
\hline Current smokers $(\geqslant 20 \mathrm{~g} /$ day) & 26.59 (12.12 to 58.35 ) & 24.98 (9.19 to 67.87$)$ & 27.08 (7.10 to 103.28$)$ \\
\hline \multicolumn{4}{|l|}{ Cardiopulmonary disease } \\
\hline No smokers & 1.00 & 1.00 & 1.00 \\
\hline Passive smokers & $0.73(0.51$ to 1.04$)$ & $1.10(0.54$ to 2.23$)$ & $0.64(0.42$ to 0.97$)$ \\
\hline Former smokers & 1.52 (1.14 to 2.03 ) & $1.76(1.24$ to 2.51$)$ & $1.36(0.70$ to 2.66$)$ \\
\hline Current smokers ( $\leqslant 9 \mathrm{~g} /$ day) & $1.16(0.83$ to 1.60$)$ & $1.36(0.90$ to 2.03$)$ & $1.04(0.56$ to 1.93$)$ \\
\hline Current smokers ( 10 to $\leqslant 19 \mathrm{~g} /$ day) & 1.85 (1.38 to 2.47$)$ & 2.12 (1.48 to 3.03$)$ & $1.72(0.92$ to 3.20$)$ \\
\hline Current smokers ( $\geqslant 20 \mathrm{~g} /$ day) & 2.51 (1.94 to 3.26$)$ & $2.90(2.10$ to 4.00$)$ & $1.80(0.92$ to 3.54$)$ \\
\hline
\end{tabular}

mortality nor on the cardiopulmonary mortality after adjustment for air pollutants (data not shown).

\section{Sensitivity analysis}

Restricting the analysis based on 18 areas to the first 10 years (until 1986), the same results in the estimated associations between air pollution and mortality were observed leading wide CIs according to the smaller number of cases (data not shown). Until 1986, 489 deaths occurred: 123 deaths for cardiopulmonary disease and 42 for lung cancer.

A sensitivity analysis was performed to assess the potential influence of subjects lost to follow up. Results were not different from those excluding subjects lost to follow up. The validity of the proportional hazards assumption was tested for gender by integrating an interaction with time in the final Cox models. This interaction was significant when studying cardiopulmonary mortality. In this case a stratification on gender was made.

\section{DISCUSSION}

The analysis of the PAARC study conducted on all 24 areas in a first step did not show significant relations between air pollution and mortality in a large sample of the French population over a 25 year period. The second step analysis based on 18 areas after excluding those likely influenced by traffic exhibited significant relations. Results show the importance of excluding traffic related monitoring stations as the associations were only significant after exclusion of such areas. Overall, results confirm published findings from the American 7 and European studies. ${ }^{24}$

The initial aim of the PAARC survey was to assess the relations between air pollution and ventilatory function and the prevalence of respiratory symptoms. In each city, areas were chosen with contrasted levels of air pollution, and a fixed air monitoring station was implanted especially for the study, very close to the residence of the subjects.

\section{Limitation of exposure data}

The number of carefully controlled measurement sites (24 areas) provide to the PAARC survey a large range of exposure level. Nevertheless, our results show the influence of exposure assessment on the estimation of the association between air pollution levels and 25 year mortality. For six areas, the
$\mathrm{NO} / \mathrm{NO}_{2}$ ratio of the monitoring data was high, suggesting that the exposure measure was heavily influenced by the local traffic and, so, non-representative of the mean exposure of the population of the entire area. NO is the principal component of the NOx emissions by cars. The somewhat arbitrary criteria $\left(\mathrm{NO} / \mathrm{NO}_{2}>3\right)$ we chose is an indication of the closeness of the station to a very busy roadside, ${ }^{22} 2526$ and corresponds in the study to the upper quartile of all monitor stations. Our choice was reinforced by the fact that the stations with a high $\mathrm{NO} / \mathrm{NO}_{2}$ ratio had a high (upper quartile) level of black smoke, too, suggesting an overestimation of the mean population exposure in the area (table 1 ). It is reassuring that some of the stations of the excluded areas were already qualified as potentially non-representative due to an important road traffic at the time of the survey. We hypothesise that the monitoring data at the beginning of the PAARC study in these six areas were not representative of the mean exposure of the population in the entire areas, and keeping them in the analysis led to a measurement error which tends to decrease the association between air pollution and mortality.

In the Harvard Six Cities study, exposure was assessed on a longer period but with only one air monitoring station in each city, and in the ACS study individual exposure was assessed by zip code. In the AHSMOG study, interpolations of ambient air concentrations from fixed monitoring stations (within $50 \mathrm{~km}$ ) to zip code centroids of work and home locations of study participants were used. In that study, the assessment of $\mathrm{PM}_{10}$ was mostly indirect, using a conversion from TSP measures based on a two year period with both measures, ${ }^{27}$ giving imprecise assessment as TSP levels may have changed differently with time than $\mathrm{PM}_{10}$ or $\mathrm{PM}_{2.5}$ levels. ${ }^{28}$ It is a strength of our study that the subjects studied lived in a $2.3 \mathrm{~km}$ distance from the monitoring station. Recently, the cohort from Netherlands used a different approach based on a geographic information system. The authors characterised exposure with the measured regional and urban background concentration and an indicator variable for living near major roads. ${ }^{29}$ The difference with the US study is that they assessed exposure on a smaller spatial scale.

In the PAARC survey, air pollution data were recorded for only three years, but to be included in the study, subjects had 


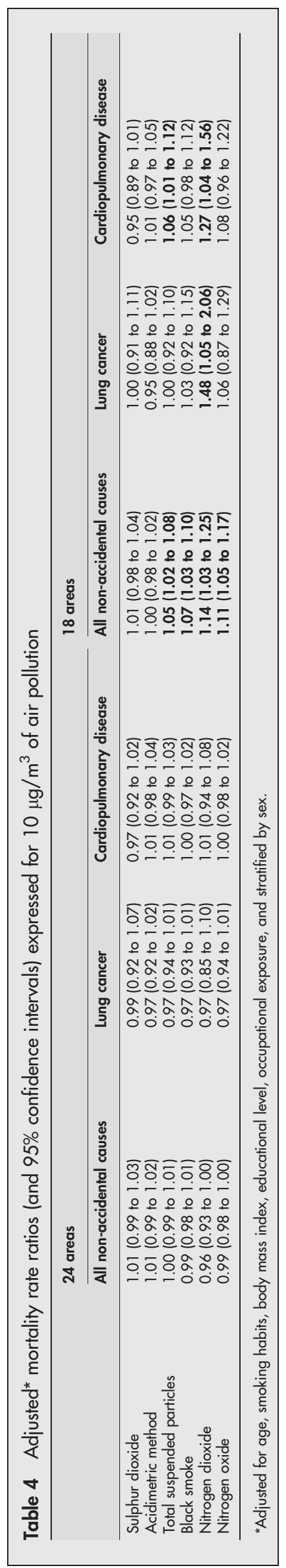

to be in the area for three years or more. At baseline in 1974, $50 \%$ of the individuals had stayed more than nine years in the same residence (25th centile: 5 years; 75 th centile: 16 years). Even if we estimate that all subjects moved at the beginning of the study, the means levels of air pollution in 197476 will be a good estimate of the chronic exposure on the period before their inclusion. Our analysis does not take into account the evolution of air pollution over time. The assessment of 23 years' black smoke evolution conducted in Bordeaux, based on air pollution networks showed a decrease in pollution whatever the area. ${ }^{14}$ However, although decreased, the differences at the beginning of the period between areas remained 23 years later in a smaller proportion. Furthermore, a recent study conducted in France in the same cities confirmed the decrease in levels of air pollution whatever the city. ${ }^{23}$

Comparing our results with published findings from the six cities, the ACS and AHSMOG studies are somewhat limited because available data to update the estimates of air pollution indicators are different. The great majority of epidemiological studies in Europe used particle metrics such as black smoke for which large datasets are available. Furthermore, diesel traffic contributes substantially to current outdoor air pollution in French urban areas, whereas in north America the proportion of diesel traffic is relatively weak. Hoek et al used black smoke and $\mathrm{NO}_{2}$ in the cohort of the NLCS study, and our results for these pollutants and mortality are similar. Assuming that BS correspond to particles of an aerodynamic diameter $<4.5 \mu \mathrm{m},{ }^{30}$ results may be compared to those on $\mathrm{PM}_{2.5}$. In the ACS study, the adjusted mortality RR associated with a $10 \mu \mathrm{g} / \mathrm{m}^{3}$ change in $\mathrm{PM}_{2.5}$ was 1.06 (1.02 to 1.11 ) and 1.07 ( 1.03 to 1.10 ) in the PAARC study. Therefore, observations of a long term effect of particulate air pollution on mortality are consistent in the USA and in Europe.

\section{Statistical analysis}

Whatever the study, statistical analyses were based on Cox proportional hazard models. In the analysis of the six cities and the ACS studies, the time variable was survival time from date of enrolment. The subjects were stratified according to sex and five year age groups; each sex-age group had its own baseline hazard. The AHSMOG study used age as a covariable or as the time variable (for lung cancer mortality). For our analysis of the PAARC study, we used models with age as the time variable and with delayed entry, in order to adjust mortality risk non-parametrically for age. However, conclusions were similar when modelling parametrically the effect of age (results not shown).

\section{Confounding factors}

The analysis took into account a substantial number of confounding factors, recorded by questionnaire in 1974-76. However, smoking habits and occupational exposure may have changed in the follow up period. The loss of information on smoking habits is not important because subjects were 25-50 years old at recruitment, and it is uncommon to start smoking after this age. ${ }^{31}$ Smoking habits were taken into account qualitatively (never, past smokers) and quantitatively with the number of grams of tobacco/day. Passive smoking was also included in the models. The strong expected associations of the smoking variables with specific causes of death confirm the relevance of the chosen indicators. Occupational exposure to dust, gases, and fumes could also evolve during these 25 years, but no information was available. The occupational exposure based on a population specific job exposure matrix ${ }^{15}$ was shown previously in the analysis of morbidity to perform better than individual self-reported exposure in large populations, such as in the PAARC survey. We found that occupational exposure or 

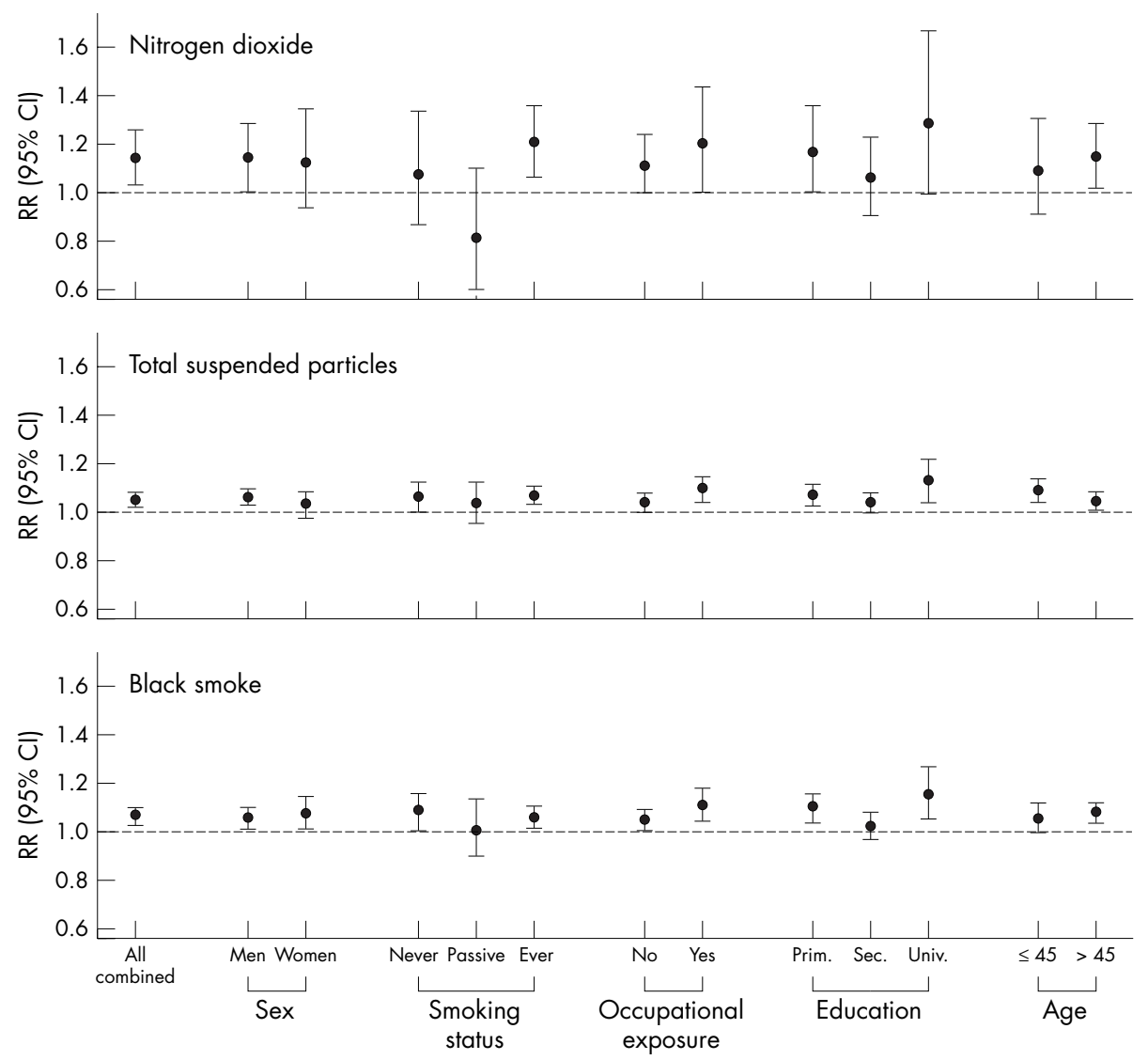

Figure 2 All-causes adjusted mortality rate ratios expressed for $10 \mu \mathrm{g} / \mathrm{m}^{3}$ of air pollution after stratifying by sex, smoking habits, occupational exposure, educational level, and adjusting for all other risk factors; 18 areas with $\mathrm{NO} / \mathrm{NO}_{2}<3$ (in ppb).

smoking habits seems to increase the effect of particles, a. pattern possibly related to cumulative exposure to oxidants, which play a critical role in respiratory diseases. ${ }^{32} 33$

A reanalysis performed by the HEI showed that the association between an increase in fine particles and mortality tended to be higher for individuals without a high school education than for those who had completed high school or those with more than a high school education. ${ }^{34} \mathrm{~A}$ modifying effect of educational level was observed on the association of TSP to all-cause mortality (clear effect only for subjects with a primary level of education), but the pattern was not consistent for the other pollutants, or the other causes.

Available data regarding the mobility of the subjects showed that less than half of the subjects were likely to be in the same city after 25 years; the analysis at 10 years was also an attempt to decrease the influence of mobility on exposure in relation to mortality. Regarding the American studies, mobility was only assessed at 12 years in the Six Cities study and varied between $13 \%$ and $32 \%{ }^{34}$ Relative risk of fine particle exposure for all-cause mortality in the nonmover group was comparable to that for the entire sample. For the other studies the analysis was always based on the residential address at the time of recruitment.

Quantification of the health impact of air pollution has increasingly become a critical component in the policy discussion. ${ }^{935}$ Estimation and interpretation of the long term results are difficult. Nevertheless, results of cohort studies are critical in this debate, ${ }^{36}$ as an assessment based solely on results of time-series studies could seriously underestimate the impact of air pollution on long term mortality. The American cohort studies found significant associations between particles and long term mortality. These results have been questioned, ${ }^{36}$ but their validity and their robustness have recently been confirmed by the reanalysis of the HEI. ${ }^{34}$ Our results show an association between air pollution levels assessed in the 1970s and long term mortality in France, when we exclude from the analysis the areas with monitoring data with a high $\mathrm{NO} / \mathrm{NO}_{2}$ ratio indicative of an overestimation of the mean exposure of the entire area. Caution in the interpretation of our data is needed due to the somewhat crude character of the simple criteria we used to select the areas.

Knowledge about the biological mechanisms of parti$\operatorname{cles}^{37}{ }^{38}$ or nitrogen dioxide ${ }^{38}$ on human health has progressed, and has shown that air pollution induces lung damage (inflammation), reduces lung function, and leads to respiratory distress and cardiovascular disease. In the light of current scientific knowledge, our results are consistent with other available data which support the hypothesis of a causal relation between air pollution and health. ${ }^{39}$ However, further European data are necessary to understand better the health impact of air pollution.

\section{ACKNOWLEDGEMENTS}

Supported in part by the program Primequal-predit and by APPA (Association pour la Prévention de la Pollution Atmosphérique). The authors are grateful to the coordinators of the PAARC survey who set up the study 25 years ago: D Brille, P Bourbon, and J Lellouch. They thank T Baldi, C Barnshaw, M Berlier, N Bousquet, A Chamming's, F Sampogna, the city halls, P Myquel, J Chavanne at the IFR69-CRI, the RNIPP at INSEE, and E Michel from the SC8 at INSERM who helped with the collection of vital status and causes of deaths. They also thank G Pédrono for her help in spatial clustering analyses, J Lellouch for comments on the first version, and an 
anonymous reviewer for suggesting to take into account the $\mathrm{NO} / \mathrm{NO}_{2}$ ratio in the exposure assessment.

\section{Authors' affiliations}

L Filleul, S Vandentorren, A Cantagrel, P Brochard, J-F Tessier, I Baldi, Laboratoire Santé Travail Environnement, Bordeaux, France

V Rondeau, INSERM E0338, Biostatistique, Bordeaux, France

N Le Moual, I Annesi-Maesano, F Kauffmann, Unité INSERM U472,

Villejuif, France

D Charpin, D Vervloet, UPRES 3287, Marseille, France

C Declercq, Observatoire Régional de la Santé Nord-Pas-de-Calais, Lille, France

F Neukirch, Unité INSERM U408, Paris, France

C Paris, Centre Hospitalier Universitaire de Roven, France

Competing interests: none declared

\section{REFERENCES}

1 Samet JM, Dominici F, Curriero FC, et al. Fine particulate air pollution and mortality in 20 US Cities, 1987-1994. N Engl J Med 2000:343:1742-9.

2 Katsouyanni K, Touloumi G, Spix C, et al. Short term effects of ambient sulfur dioxide and particulate matter on mortality in 12 European cities: results from time series data from the APHEA project. BMJ 1997;314:1658-63.

3 Zmirou D, Schwartz J, Saez M, et al. Time-series analysis of air pollution and cause-specific mortality. Epidemiology 1998;9:495-503.

4 Dockery DW, Pope III CA, Xu X, et al. An association between air pollution and mortality in six US cities. N Engl J Med 1993;329:1753-9.

5 Pope CA, Thun MJ, Namboodiri MM, et al. Particulate air pollution as a predictor of mortality in a prospective study of US adults. Am J Respir Crit Care Med 1995;151:669-79.

6 Abbey DE, Nishino N, McDonnell WF, et al. Long-term inhalable particles and other air pollutants related to mortality in nonsmokers. Am J Respir Crit Care Med 1999;159:373-82.

7 Pope CA, Burnett RT, Thun MJ, et al. Lung cancer, cardiopulmonary mortality, and long-term exposure to fine particulate air pollution. JAMA 2002;287:1132-41

8 Hoek G, Brunekreef B, Goldbohm S, et al. Association between mortality and indicators of traffic-related air pollution in the Netherlands: a cohort study. Lancet 2002;360:1203-9.

9 Kunzli N, Kaiser R, Medina S, et al. Public-health impact of outdoor and traffic-related air pollution: a European assessment. Lancet 2000;356:795-801.

10 PAARC, Groupe coopératif. Pollution atmosphérique et affections respiratoires chroniques ou à répétition. Méthodes et matériel. Bull Europ Physiopath Resp 1982;18:87-99

11 PAARC, Groupe Coopératif. Pollution atmosphérique et affections respiratoires chroniques ou à répétition, résultats et discussion. Bull Europ Physiopath Resp 1982:18:101-16.

12 Baldi I, Tessier JF, Kauffmann F, et al, and le groupe coopératif PAARC. Prevalence of asthma and means levels of air pollution: results from the French PAARC survey. Eur Respir J 1999;14:132-8.

13 Filleul L, Vandentorren S, Baldi I, et al. Estimation de la mobilité résidentielle des sujets d'une étude vingt-cinq ans après la phase $\mathrm{d}^{\prime}$ inclusion. Rev Epidemiol Sante Publique 2000;48:3S135.

14 Filleul L, Baldi I, Quenel P, et al. Long-term air pollution indicator assessment: example of black smoke in Bordeaux, France. J Expo Anal Environ Epidemiol 2002;12:226-31.

15 Le Moual N, Bakke P, Orlowski E, et al. Performance of population specific job exposure matrices (JEMs): European collaborative analyses on occupational risk factors for chronic obstructive pulmonary disease with job exposure matrices (ECOJEM). Occup Environ Med 2000;57:126-32.
16 Tong L, Spitz MR, Fueger JJ, et al. Lung carcinoma in former smokers. Cancer 1996;78:1004-10.

17 Cox DR. Regression models and life tables (with discussion). Journal of the Royal Statistical Society Series B 1972;34:187-220.

18 Commenges $\mathrm{D}$, Letenneur $\mathrm{L}$, Joly $\mathrm{P}$, et al. Modelling age-specific risk: application to dementia. Stat Med 1998;17:1973-88.

19 Commenges D, Letenneur L, Joly P. Re: "Serum transferrin saturation, stroke incidence, and mortality in women and men. The NHANES I Epidemiologic Follow-up Study". Am J Epidemiol 1997;146:683-4.

20 Ihaka R, Gentleman R. A language for data analysis and graphics. J Computational Graphical Statistics 1996;5:299-314.

21 Therneau TM, Grambsch PM, eds. Modeling survival data: extending the Cox model. New York: Springer, 2000

22 Agence de l'Environnement et de la Maîtrise de l'Énergie. Classification and criteria for setting up air-quality monitoring stations. Paris: Ademe, 2002:70.

23 Zeghnoun A, Eilstein D, Saviuc P, et al. Surveillance des effets à court terme de la pollution atmosphérique sur la mortalité en milieu urbain: résultats de l'étude de faisabilité dans 9 villes françaises. Rev Epidemiol Sante Publique 2001;49:3-12.

24 Hoek G, Brunekreef B, Goldbohm S, et al. Association between mortality and indicators of traffic-related air pollution in the Netherlands: a cohort study. Lancet 2002;360:1203-9.

25 Peace H, Owen B, Raper DW. Identifying the contribution of different urban highway air pollution sources. Sci Total Environ 2004:334-5, 347-57.

26 Quality Expert Group. Nitrogen dioxide in the United Kingdom. London, Department for Environment, Food and Rural Affairs, 2004 (hitp:// www.defra.gov.uk/environment/airquality/aqeg/nitrogen-dioxide// (accessed 9 November 2004).

27 Abbey DE, Hwang BL, Burchette RJ, et al. Estimated long-term ambient concentrations of PM10 and development of respiratory symptoms in a nonsmoking population. Arch Environ Health 1995;50:139-52.

28 Brunekreef B. All but quiet on the particulate front. Am J Respir Crit Care Med 1999; 159:354-6.

29 Hoek G, Fischer P, Van Den Brandt P, et al. Estimation of long-term average exposure to outdoor air pollution for a cohort study on mortality. J Expo Anal Environ Epidemiol 2001;11:459-69.

30 Goodman P, Dockery DW, Clancy L. Cause-specific mortality and the extended effects of particulate pollution and temperature exposure. Environ Health Perspect 2004;112:179-85.

31 Doll R, Peto R, Wheatley K, et al. Mortality in relation to smoking: 40 years' observations on male British doctors. BMJ 1994;309:901-11.

32 Churg A, Wright JL. Airway wall remodeling induced by occupational mineral dusts and air pollutant particles. Chest 2002;122(6 suppl):306S-9S.

33 Monn C, Brandli O, Schindler C, et al. Personal exposure to nitrogen dioxide in Switzerland. SAPALDIA team. Swiss Study on Air Pollution and Lung Diseases in Adults. Sci Total Environ 1998;215:243-51.

34 Krewski D, Burnett RT, Goldberg MS, et al. Reanalysis of the Harvard Six Cities Study and the American Cancer Society Study of Particulate Air Pollution and Mortality. Cambridge: Health Effects Institute, 2000:246.

35 European Centre for Environment and Health, WHO working group. Quantification of the health effects of exposure to air pollution. World Health Organisation, 2001:38.

36 Kunzli N, Medina S, Kaiser R, et al. Assessment of deaths attributable to air pollution: should we use risk estimates based on time series or on cohort studies? Am J Epidemiol 2001;153:1050-5.

37 Pope CA. Epidemiology of fine particulate air pollution and human health: biologic mechanisms and who's at risk? Environ Health Perspect 2000;108:713-23.

38 WHO working group. Health aspects of air pollution with particulate matter, ozone and nitrogen dioxide. Bonn: European Centre for Environment and Health, 2003:94.

39 Filleul L, Medina S, Cassadou S. [Urban particulate air pollution: from epidemiology to health impact in public health]. Rev Epidemiol Sante Publique 2003;51:527-42. 